\title{
Biomaterials for heart valve replacement: Conjectures and refutations
}

\author{
Muralidhar Padala, $\mathrm{PhD}$
}

\footnotetext{
From the Structural Heart Research \& Innovation Lab, Division of Cardiothoracic Surgery, Carlyle Fraser Heart Center, Emory University, Atlanta, Ga.

Disclosures: Author has nothing to disclose with regard to commercial support.

Received for publication May 26, 2016; accepted for publication May 27, 2016; available ahead of print June 25, 2016.

Address for reprints: Muralidhar Padala, PhD, Structural Heart Research \& Innovation Lab, Division of Cardiothoracic Surgery, Carlyle Fraser Heart Center, Emory University, 380B Northyards Blvd, Atlanta, GA 30313 (E-mail: spadala@emory.edu)

J Thorac Cardiovasc Surg 2016;152:1175-6

$0022-5223 / \$ 36.00$

Copyright (C) 2016 by The American Association for Thoracic Surgery

http://dx.doi.org/10.1016/j.jtcvs.2016.05.055
}

Science does not rest upon solid bedrock, but rises above a swamp. It is like a building erected on piles, the piles are driven down from above into the swamp. We cease our attempts to drive our piles into a deeper layer, not because we have reached a firm ground, but only because we are satisfied that they are firm enough to carry the structure for the time being.

\section{—Adapted from Logik Der Forschung,}

Karl Popper, 1959

The quest for an optimal aortic valve replacement that is durable, resists calcification, achieves good hemodynamic parameters, and adapts to cyclic mechanical loading remains largely unfulfilled. Pulmonary autografts in the aortic position are the only living valve substitutes, but the Ross procedure is grossly underutilized due to its perceived complexity. Decellularized homograft/ xenograft/pericardium are closer to a living substitute because the native extracellular matrix skeleton is expected to recellularize in situ and develop the trilayered native valve anatomy. However, use of enzymes (DNAase and RNAase) and harsh detergents for decellularization lead to extracellular matrix degeneration and early structural failure of these grafts. Tissue engineering approaches to populate synthetic scaffolds with autologous cells remain rudimentary, despite significant investment. Glutaraldehyde fixed decellularized scaffolds have been adopted clinically due to reduced antigenicity and stability against proteolytic damage. Stented valves made from this material faced early failures, but the current generation of valves has a durability of 15 to 20 years (Edwards Pericardial Valve; Edwards LifeSciences, Irvine, Calif) in adults, but $<10$ years in pediatric patients. ${ }^{1}$ Early calcification and patient-prosthesis mismatch remain the primary cause of valve failure in growing children. The need for a biomaterial that can resist calcification and grow with the child is valid, and current solutions that address these problems are few.

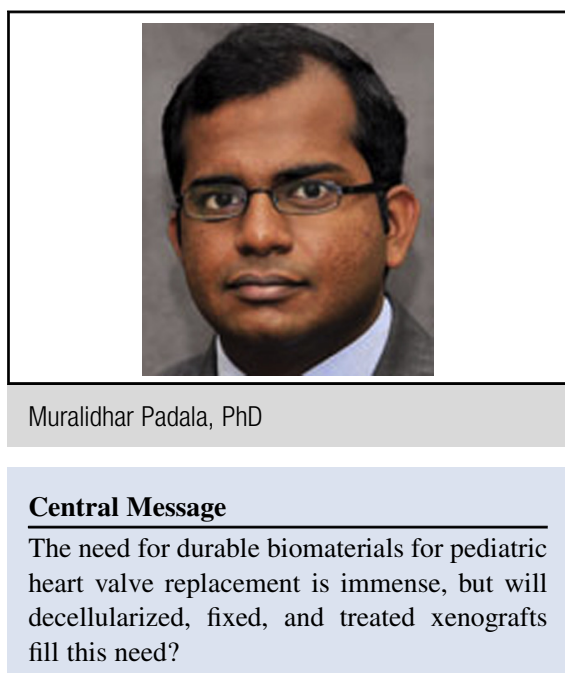

See Article page 1167.

Meuris and colleagues ${ }^{2}$ report their preclinical experience with aortic valve reconstruction with a new glutaraldehyde fixed decellularized bovine pericardium (CardioCel; Admedus Inc, Malaga, Australia). The tissue is prepared using a multistep ADAPT treatment, consisting of decellularization, lipid extraction, fixation in low concentration monomeric glutaraldehyde, and treatment with a proprietary detoxification process to remove excess unbound glutaraldehyde. Instead of using this material in a stented valve prosthesis, the authors use the Ozaki aortic valvuloplasty technique, ${ }^{3}$ which preserves native aortic root motion and allows its growth. In 3 sheep followed for up to 6 months, the neoleaflets were pliable, allowed sufficient diastolic closure, and calcification was observed only in 1 valve out of 3 . Preliminary evidence demonstrates low aortic valve gradient, and a large coaptation length evident from echocardiography. The authors should be congratulated for their efforts with this new material.

The first question that arises from this study is the clinical need for a xenograft material for aortic valve reconstruction. Ozaki and colleagues ${ }^{3}$ reported successful use of glutaraldehyde fixed autologous pericardium with very low rates of calcification or valve degeneration. Unavailability of healthy native pericardium is rare, and is encountered only in patients undergoing redo cardiac surgery or those with inflammation of the pericardium. The benefits offered by autologous tissue trump xenograft tissue, despite decellularization and treatment to resist calcification. The 
second question is the scientific basis for the superior results expected from CardioCel when compared with other existing tissue treatments. In a rat subcutaneous model, tissue treated with ADAPT demonstrated less calcification compared with fixed tissue without anticalcification treatment. ${ }^{4}$ Such a result is expected because tissue without anticalcification treatment can trigger a rapid immune response. When compared against valve cusps treated with Freestyle (Medtronic Inc, Minneapolis, Minn) or Prima Plus (Edwards LifeSciences) devices, resistance to enzymatic degradation and calcification were comparable. ${ }^{5}$ Although use of lower-concentration glutaraldehyde $(0.05 \%)$ is a potential benefit, reduced leaflet stiffness could lead to higher collagen fibril strain and accumulate damage. The third question that arises from the reported results is the potential for autologous recellularization of this material. Examination of explant photographs and histopathology slides from this study and others using this material demonstrate a fibrous sheath/pannus covering the valve, with acellularity of the medial layers. This fibrous sheath is rich in collagen and is highly cellular, but it is misleading to consider this to be physiologic adaptation, growth, or recellularization. Glutaraldehyde crosslinking creates a hydrophobic surface that reduces the ability of cells to adhere and become motile to repopulate the treated tissue. Furthermore, whereas detoxification could effectively remove the unbound glutaraldehyde, the free aldehyde groups on the glutaraldehyde that is covalently bound to the collagen is cytotoxic.

Is CardioCel the solution to our problems with pediatric valve replacement? The science underlying this technology seems comparable to other tissue treatments that have also demonstrated excellent preclinical outcomes but have relatively poor clinical data. Ultimately, time will tell whether some hidden chemistry in this material will position it as a better leaflet substitute, or whether the old problems with these tissues will refute their conjecture.

\section{References}

1. Bourguignon T, El Khoury R, Candolfi P, Loardi C, Mirza A, Boulanger-Lothion J, et al. Very long-term outcomes of the Carpentier Edwards Perimount aortic valve in patients aged 60 or younger. Ann Thorac Surg. 2015;100:853-9.

2. Meurius B, Ozaki S, Neethling W, De Vleeschauwer S, Verbeken E, Rhodes D, et al. Trileaflet aortic valve reconstruction with a decellularized pericardial patch in a sheep model. J Thorac Cardiovasc Surg. 2016;152:1167-74.

3. Ozaki S, Kawase I, Yamashita H, Uchida S, Nozawa Y, Takatoh M. A total of 404 cases of aortic valve reconstruction with glutaraldehyde-treated autologous pericardium. J Thorac Cardiovasc Surg. 2014;147:301-6.

4. Neethling WM, Glancy R, Hodge AJ. Mitigation of calcification and cytotoxicity of a glutaraldehyde preserved pericardial matrix: improved biocompatability after extended implantation in the subcutaneous rat model. J Heart Valve Dis. 2010;19: 778-85.

5. Neethling WM, Glancy R, Hodge AJ. ADAPT-treated porcine valve tissue (cusp and wall) versus Medtronic Freestyle and Prima Plus: crosslink stability and calcification behavior in the subcutaneous rat model. J Heart Valve Dis. 2004;13:689-96. 